\title{
M.C. Colombani, J. Ferguson y J. M. Gerardi (Comps.) (2018). Miradas interdisciplinarias sobre el Mundo Antiguo. Encuentros de Historia, Filosofía y Literatura, Mar del Plata, Universidad Nacional de Mar del Plata, pp. 394
}

\author{
Rocío Seiler \\ Universidad Nacional de Mar del Plata, Argentina \\ seilerrocio@gmail.com
}

Miradas interdisciplinarias sobre el Mundo Antiguo. Encuentros de Historia, Filosofía y Literatura recopila investigaciones procedentes del área de Literatura, Filología, Semiología y de Historia Antigua que se aproximan -desde una mirada histórica- a diversas cuestiones sociales desarrolladas en la antigüedad egipcia, romana y griega. Los compiladores, María Cecilia Colombani, Juan Ferguson y Juan M. Gerardi, son docentes e investigadores de la Universidad Nacional de Mar del Plata y participan de proyectos conjuntos en diversas universidades nacionales y extranjeras. A lo largo de la introducción y los trece capítulos que comprende el ejemplar, los compiladores reúnen trabajos de distintos profesionales de universidades nacionales y extranjeras que desarrollan temáticas vinculadas a sus respectivas especializaciones.

El primer capítulo presenta una investigación de Marcelo Campagno titulada Mito, cuento, historia. A propósito de los relatos egipcios de La contienda entre Horus y Seth y de Verdad y Mentira. Este interesante apartado explora dos relatos pertenecientes a la literatura egipcia antigua. Ambos explicitan una disputa entre dos rivales antagónicos: Horus vs. Seth, Verdad vs Mentira. Mientras que el primero da cuenta de la beligerancia entre ambos, el segundo relata una contienda entre dos hermanos -Verdad y Mentira- los cuales se habían presentado ante la Enéada por un conflicto engañoso. Establecidos los relatos, a partir de un análisis literario del mito y el cuento, Campagno sostiene que es lícito diferenciar el primero como práctica discursiva específica respecto de otras prácticas, pues en su análisis es necesario distinguir dos niveles, a saber: el del mito en sí, al que no se puede acceder de manera directa, y el de las distintas realizaciones a través de las cuales el mito se manifiesta. En esa sintonía, mientras que La contienda parecía ser una forma de realización literaria del mito donde dos deidades divinas luchaban entre sí, en el cuento de Verdady Mentira, los dioses brillaron por su ausencia.

El segundo capítulo corresponde a Juan R. Ferguson y es denominado Trabajo especializado, división del trabajo y trabajadores durante el Reino Medio egipcio (c. 2055-1650 a.C.): continuidades y rupturas en los registros de las minas del Sinaí. A partir de un conjunto de fuentes escritas e iconográficas, el autor analiza la organización de la mano de obra y el envío de expediciones a las minas de la península del Sinaí, buscando identificar las categorías de trabajadores implicados y el control estatal al que estuvieron sujetos. Luego de plantear un debate historiográfico en torno al marco conceptual para el abordaje de las estructuras socioeconómicas del Antiguo Egipto, el autor aborda la exploración de las minas del Sinaí en el Reino Medio. En este punto, Ferguson describe las expediciones que partían desde Egipto hacia la península y detalla la 
labor del cuerpo expedicionario conformado por los trabajadores de las canteras sujetos a la corvea. El autor insiste sobre una cuestión importante, esto es, la permanencia a través del tiempo del esquema de división del trabajo y equipos pequeños de trabajadores, permitiéndole al Estado contar con una fuerza productiva importante que, en palabras del autor, se siguió utilizando con éxito en períodos posteriores a su creación.

El capítulo tercero corresponde a María Cecilia Colombani y se titula La singularidad de la "versión" Hesiodo. La autora analiza dos poemas hesiódicos: Teogonia y Trabajos y Días estudiando cómo el linaje atraviesa el género discursivo de la obra y responde a la vez a un télos. En consecuencia, explica que la lógica del linaje operaba como un modelo de organización, donde la figura de Zeus aparecía como un hito de luminosidad. En ese sentido, la construcción espacio temporal respondía a un orden cósmico que buscaba la legitimación de los dioses. Por este motivo, la autora plantea pensar Trabajos y Días desde el contenido y Teogonía a partir del orden discursivo. Según Colombani, Hesíodo logra plasmar en su obra-mediante el mito- un nuevo imaginario donde el linaje emergió como el operador discursivo que buscó ordenar y clasificar la realidad, así como definir estructuras mentales en un momento bisagra de extrema heterogeneidad social.

El capítulo número cuatro pertenece a Ana Iriarte y es curiosamente titulado Casandra o el logos desautorizado en la Atenas democrática ( $y$ en Wikipedia). En él, la autora analiza cómo se presenta a Casandra en el contexto de la tragedia griega conduciéndonos -a través de una selección iconográfica-a las andanzas de Casandra por la guerra de los hombres, que la tradición homérica relata en la Guerra de Troya. Dentro de ese análisis, se inscribe su violación por el guerrero griego Áyax. En efecto, a partir de una selección de obras pictóricas representativas del acto, la autora puntualiza que la violación de Casandra había sido atendida por la iconografía antigua, narrada en imágenes, antes de convertirse en paradigma de crueldad bélica en la tradición literaria que conocemos. Lo digno de observar para la autora, desde la perspectiva identitaria que le ocupa, es la cantidad de información que proporciona la imagen. Mientras que la imaginería griega tendía a cubrir el cuerpo femenino, el desnudo masculino era habitual en las representaciones artísticas. Los poetas habían convertido a Casandra en el paradigma de crueldad bélica y post-bélica. De la mano de las pinturas y esculturas modernas que la autora fue analizando a lo largo de su investigación, se observa entonces el poder de la supervivencia de la figura de Casandra. Y en Wikipedia, casualmente se reproduce la tradición artística griega de Casandra, en la medida en que insiste en su dimensión de herida/heroína de guerra.

El quinto capítulo de esta obra se designa Competiciones deportivas en la Antigua Grecia y está a cargo de Fabio de Souza Lessa quien analizó la violencia experimentada por los helenos durante las competencias deportivas y, específicamente al pancracio habiendo sido considerada una de las prácticas más violentas. La violencia es un problema que ha agobiado a la humanidad desde su origen. Para los griegos la solución había sido la educación. En relación a lo anterior, las actividades gimnásticas se convirtieron en un elemento indispensable de la formación del ciudadano enmarcada en la búsqueda de lo bueno y hermoso, y en esta búsqueda de la kalokagathia, la educación del cuerpo tenía tanta importancia como la del espíritu. Es allí donde la gimnasia jugó un papel determinante en la paideia helénica, que pretendía formar buenos y bellos ciudadanos. Y es allí también donde la violencia -presente en la práctica deportiva- pudo ser entendida como una canalización de las tensiones sociales, siendo, a su vez, sinónimo de malestar social. En contraposición a la misma, el autor demuestra cómo era valorado positivamente el atleta que alcanzaba la victoria sin el uso de la violencia, resaltando asimismo la virtud, aprobación y respeto que le eran atribuidas, tanto por parte de sus conciudadanos como de sus adversarios.

El capítulo sexto pertenece a María Regina Candido y se titula Las prácticas de la magia amorosa de Simeta. Simeta se encuentra en el Idilio II, escrito por el poeta griego Teócrito de Siracusa. La autora recoge la situación vivida por una mujer enamorada de un atleta olímpico que la abandona. Por este motivo, para volver a atraer a su amado, recurrió a la magia erótica. En ese sentido, a partir de un perspicaz análisis, Candido nos demuestra cómo, desde un sencillo poema de amor, podemos recrear en nuestro imaginario situaciones pretéritas que tuvieron lugar mucho tiempo atrás, a fin de acercarnos a los sentimientos de los individuos que circulaban en medio del espacio urbano/rural. Las pequeñas composiciones poéticas que elabora Teócrito 
reflejan una realidad cotidiana con un minucioso realismo, y la autora las expone de manera perspicaz y cautivadora.

El séptimo capítulo presenta una investigación de Julián Gallego; Democracia, Estado, sujeto: pensar la politica en la Atenas clásica. Tradicionalmente se ha asociado el término democracia al siglo V. Demokratía fue la expresión que denotaba el poder del pueblo, y procedía de la conjunción de los términos dêmos y krátos, pueblo y poder. Sin embargo, el autor alude a los problemas de los diferentes significados del término demos y krátos. Para él, el sentido de la idea de democracia estaba en las prácticas donde el pueblo emergía como cuerpo político. A su vez, también implicaba conflicto, disputa. Democracia según Gallego, no significaba entonces unidad porque el modo de hacer política en la Asamblea era precisamente a partir de la división, de la lucha entre contrarios. De esa forma, el autor sostiene que dêmos no designaba un estrato social sino una capacidad política manifestada en la práctica, en las reuniones de la Asamblea, donde el pueblo, por medio de su actuación en la misma, emergía como cuerpo político que tomaba en sus manos la producción de decisiones. A través de un excelente análisis, el autor llega a conclusiones precisas que hacen a la reconfiguración de la comunidad como entidad unitaria bajo la idea genérica de pueblo, habiendo sido ésta la forma en que se efectuaba la decisión como proceso de subjetivación colectiva, y poniendo en cuestión la perspectiva historiográfica tradicional.

El siguiente capítulo se titula Otra luz para el futuro de Atenas. Eurípides, Ion. En él, María de Fátima Silva analiza desde una perspectiva filosófica, el mito sobre el origen de Atenas en el Ion de Eurípides. A partir de una conjunción entre el mito y lo humano, Atenas daba una imagen sobre sí misma y su origen como respuesta a un contexto de crisis. En ese sentido, la autora nos expone cómo Eurípides dramatizó ese mito ateniense sirviendo a dos propósitos claros: por un lado, fomentar la cohesión de los pueblos jonios en un momento de debilidad a causa de enfrentamientos bélicos y, por otro, ofrecer una prueba de la necesidad de paz entre pueblos que, después de todo, procedían de un antepasado mítico en común. A cuenta de ello, a partir de un rico abordaje bibliográfico y de fuentes, la autora demuestra cómo, a través de un mito fundador, Eurípides manifestó una crisis de la realidad social jónica de la época, pero desde su punto de vista fundacional.

El noveno capítulo presenta una investigación de Alexandre Carneiro Cerqueira Lima titulada Sympósion: entre Sophrosýne y Truphé. Estrictamente reservado a los hombres, el Simposio o Banquete era un elemento esencial de la sociabilidad griega. A partir de su análisis, el autor buscó identificar en la elite etrusca invitada al banquete, el significado que la figura del Otro tenía para los helenos practicantes del ritual y cómo la idea de Simposio, fue modificada entre los siglos VII y IV según las necesidades políticas de la época. En consecuencia, a través de un análisis sumamente interesante, el autor explora cuestiones sobre el comportamiento en los symposia, entre helenos y etruscos, reflejando asimismo que las concepciones de fiesta y de placer que poseían los griegos eran diferentes para las elites etruscas. En ese sentido, el autor recoge críticas que establecieron diferentes filósofos sobre los banquetes y demuestra cómo fueron proyectadas sobre las elites etruscas.

El décimo capítulo fue escrito por Arturo R. Álvarez Hernández y presentado bajo el título Lecturas y lectores en la poesia de Catulo. Este singular aporte nos acerca a la circulación comercial de libros en la Roma Antigua y al público receptor, analizando específicamente la labor poética del poeta latino Catulo (84-54 a.C.) y su posible alcance hacia nuevos lectores anónimos. Desde el inicio, en distintas notas al pie, el autor explica apropiadamente distintas temáticas que hacen a su investigación, haciendo posible de esta forma que los lectores ajenos a la temática desarrollada puedan tener una comprensión más clara de su perspectiva de análisis. Siguiendo la línea trazada por el autor, consideramos pertinente aquí también mencionar una de esas aclaraciones: en la Antigüedad, la recepción de los textos era una experiencia auditiva. La lectura en silencio era un caso excepcional, y los textos se oían a través del rapsoda, de un cantor individual, de un coro, de un orador, de otro lector, entre otros. De este modo, Álvarez Hernández nos adentra en la búsqueda del origen de los libros de la biblioteca de Catulo. Y es a través del ingenioso análisis de dos piezas de la obra del poeta que el autor va reconstruyendo ese público destinatario de la poesía catuliana: los Carmen 95 y 1. 
El capítulo decimoprimero fue elaborado por Juan M. Gerardi y se titula Conflictos sociales y modalidades de la protesta popular en la crisis de la república romana. Aquí, el autor analiza una faceta de la crisis de la República (el período que le ocupa específicamente es entre el 133 al 49 a.C.) desde la intervención política del populus a partir de la acción colectiva con recurso a la violencia. Según Gerardi, estas luchas fueron el resultado del poder acumulado por un sector de la sociedad que, cuando se sentía atacado de algún modo, se reunía en torno a un eje de disputa, frente al cual se movilizaba adoptando una estrategia de acción conjunta. Luego de un profundo acercamiento al debate historiográfico actual, el autor expresa su posicionamiento historiográfico y considera que las agitaciones, motines y disturbios se encontraban dentro de las expresiones políticas, siendo a la vez complementarias de las manifestaciones de la voluntad ciudadana. En este sentido, la violencia habría sido un instrumento utilizado para un fin determinado, lo que implicó un comportamiento racional, una estrategia más en el juego de la política para dirimir un conflicto. A través de ella se manifestaban intereses, formas de relaciones sociales, de procedimiento y distintos efectos dependiendo de sus protagonistas y de las dimensiones económica y política.

El anteúltimo capítulo fue escrito por Carlos G. García Mac Gaw y se titula El esclavismo romano, el modo de producción antiguo y el sistema tributario. Teoría e historiografía. En esta investigación, el autor estudia la conformación de una posición dominante en la historiografía referida a la esclavitud en el seno de la Antigüedad clásica. A la vez, nos aproxima al debate historiográfico actual en torno al estudio de la esclavitud como fuerza de trabajo que ayudó a la constitución del mercado de trabajo capitalista norteamericano. En relación a ello, el autor explica que los estudios sobre la esclavitud antigua en el marco de la economía de los últimos siglos de la República y de comienzos del Imperio, son dependientes de enfoques centrados sobre el contexto de la economía capitalista de la plantación. Por ende, a caracterización de la villa esclavista romana ha estado vinculada al estudio de los sistemas de plantaciones norteamericanos. Lo cual implica plantear una continuidad -simplista- de un sistema esclavista en escenarios muy diferentes entre sí. Bajo este supuesto, el autor desarrolla su análisis y nos ubica -desde una perspectiva marxista y a partir de una discusión dinámicaen un debate actual sobre el sistema de producción antiguo y tributario, y su relación con la esclavitud romana.

Llegamos al final de nuestro recorrido con la última obra a cargo de la Dra. Regina María da Cunha Bustamante. La misma se presenta bajo el título Espectáculos de anfiteatro en el África romana: la competición fuera de la arena. En este capítulo, la autora selecciona y estudia un mosaico datado en el siglo III, procedente de la antigua ciudad de Thysdrus, moderna El Djem, en Túnez. Luego de invitar al lector a conocer lo que fue el arte musivo en el norte del África antigua, da Cunha Bustamante se centra en el mosaico que le ocupa: un opus tesselatum que decoraba el pavimento de la entrada del frigidarium -cuarto de baño frío- de una terma en la ciudad de Thysdrus, en la rica provincia romana de África Proconsular. Los distintos edificios públicos eran espacios de socialización y de confort, lugares de reunión adonde acudían los ciudadanos, no sólo por sus usos específicos sino con el objetivo puntual de "hacer" política. Ahora bien, en este espacio no analizaremos el bello mosaico que la autora selecciona para su interpretación, pero invitamos al lector a que acceda al excelente trabajo que realiza junto con otros especialistas para descubrir lo que el mosaico revela, a través de un mensaje ubicado justo en la entrada de la primera sala del complejo termal. Entendiendo el término cultura en sentido amplio y pensándolo en función de una coyuntura, es posible aprehender la complejidad de las sociedades del pasado, siendo éste el objetivo al que apunta la autora.

Antes de finalizar, no quisiera dejar de mencionar algunos puntos relacionados con la cuestión estilística y retomar, brevemente, lo que se señaló al inicio. El libro presenta investigaciones que contienen una serie de imágenes iconográficas, mapas para que el lector se sitúe en el espacio, tablas de contenido cuantitativo y cualitativo y, por supuesto, una gran cantidad de bibliografía actualizada al final de cada capítulo para que aquellos interesados puedan acceder y muchos continuar con la propuesta de los autores. En otras palabras, en sus variadas y diferentes temáticas y perspectivas de acuerdo al área de estudio de los autores, el libro cuestiona las interpretaciones tradicionales y valoriza la documentación desde un punto de vista distinto. En este sentido, la minuciosa bibliografía constituye un nuevo testimonio de la actualidad y pertinencia de 
los estudios sometidos a consideración, estudios que presentan originalidad temática y rigor, pero a la vez están abiertos al debate académico. Precisamente es por ello que los autores apuntan a que el libro sea un texto de actualización bibliográfica y consulta académica-científica, pues nos permite tener visiones renovadas sobre viejos problemas que, si bien continuarán, de alguna manera nos van a seguir convocando para pensar y reevaluar nuestras propias perspectivas, ampliando el registro de documentación. 